\title{
Why women's groups oppose injectable contraceptives
}

\author{
N B SAROIINI*, LAXMI MURTHY**
}

*Sama Resource Group for Women and Health, G-19, 2nd Floor, Saket, New Delhi 600017 INDIA. Email:sama_womenshealth@vsnl.net, *"Saheli, Shop \#105-106, Under Defence Colony Flyover Market, New Delhi 600024 INDIA. Email saheliwomen@hotmail.com

The following statement is based a letter to Mr A Ramadoss, Union Minister for Health and Family Welfare, signed by 62 individuals and health organisations in India. It was written in response to a national workshop on October 27-29, 2004, organised by Parivar Seva Sanstha, in collaboration with the government of India, UNFPA and the Packard Foundation through the Population Foundation of India to expand contraceptive choices with the introduction of injectable contraceptives.

As concerned scientists, women's groups and health activists, we are advocates of voluntary birth control and the right of a woman to control her fertility with safe contraceptive choices, which are user controlled. With this conviction, for the last two decades we have opposed the introduction of injectable contraceptives in the family planning programme.

In the bid to meet unrealistic population control targets and as part of liberalisation policies, Indian authorities have relaxed drug regulations in order to expedite the introduction of longacting, invasive, hazardous contraceptives into India. This will subject millions of Indian women to long-acting hormonal contraceptives such as injectables (Net En and Depo Provera) and sub-dermal implants (Norplant), likely to cause irreversible damage to their own and their progeny's health.

The injectable contraceptive Depo-Provera was approved for marketing in India in 1993 without the mandatory Phase 3 trials. The American multinational Upjohn (since bought over by Pfizer) thus gained access to one of the largest markets for contraceptives without following requirements.

Women's groups, health groups and human rights groups have opposed the introduction of injectables given the potential for abuse, non-completion of mandatory trials and the lack of accountability of pharmaceutical agencies. An analysis of major studies calls for a complete ban on injectable contraceptives and particularly their introduction in the public (National Family Welfare Programme) sphere.

\section{Adverse health impact}

Severe side-effects of Net-En and Depo-Provera include menstrual disorders, cessation of the monthly cycle or irregular bleeding, general weakness, migraine headaches, and severe abdominal cramps. In a country where a large percentage of women in the reproductive age suffer from anaemia, irregular and heavy bleeding can have catastrophic consequences. Studies have shown that injectable contraceptives like Depo-
Provera can also lead to osteoporosis. This can have grave consequences for poor women with low bone density due to poor nutritional status. Depo-Provera has been indicted for climacteric-like syndrome;irreversible atrophy of the ovaries and endometrium; deaths due to thrombo-embolism; increased risk of HIV infection from an infected partner; increased risk of Down Syndrome in babies born to women users; increased chances of still births; increase in the risk of breast cancer, cervical cancer including carcinoma in situ; doubts regarding the return of fertility after discontinuation of the drug, and so on.

\section{Inadequate infrastructure and accountability}

In the case against the injectable Net En, filed in the Supreme Court in 1986 against the Union of India, ICMR, DCGI and others by Saheli and other women's groups, the government admitted at the close of the case in 2000 that mass use of Net En in the FP programme was not advisable. This is a recognition of the potential risks and the need for close monitoring and followup.

Depo-Provera is hazardous for women in all circumstances. Moreover, administration requires ruling out contra-indications and close monitoring over long periods. Such monitoring is totally absent in this country. Poor women who visit government hospitals where injectables would be offered in the family planning programme would be treated as 'living laboratories'.

As for the NGO sector, the government of India has not evolved definitive standards for NGOs in terms of care, follow-up or accountability. Hence, our core concerns on women's health and safety remain unaddressed here as well.

\section{Dubious post-marketing surveillance in India}

A five-year post-marketing surveillance study (PMS) was to have been done in place of the final stage of clinical trials. Its results have not been made public. In this case, post marketing surveillance has translated into private marketing of the drug. This is hardly surprising given that PMS was conducted by Upjohn, which profitted from the results of the research. This raises serious doubts about the scientific objectivity of the data and its analysis. Scrutiny of PMS data reveals that each woman user is included in the study for five injections, three months apart. Thus, the study covers each woman user for 15 months only - though DMPA is intended as a spacing method for at least two to three years. Further, 15 months is not adequate to assess long-term effects. It is unscientific to declare Depo Provera as 'safe' on the basis of inadequate data. 
The following serious concerns remain unaddressed in the PMS:

- The potential side-effect of bone density loss and subsequent increased risk of osteoporosis has not been studied, though the PMS had a separate budget to monitor by densitometry. This is of great significance in India where bone density among women is likely to be low.

- Cancer risk has not been studied, though studies in other countries show that increased risk of breast cancer -especially in younger women- cannot be ruled out. Assessment of return of fertility has not been incorporated in the study design - in a contraceptive being promoted as a spacing method. The effect of DMPA on progeny conceived immediately on cessation of use of DMPA has also not been studied.

- Problems such as amenorrhoea, irregular bleeding, generalised weakness and lethargy, migraine headaches, pain in the abdomen and severe abdominal cramps have been considered by the researchers to be "non-serious" medical events. From a user's perspective, these side-effects could be debilitating and hamper daily activities and affect one's well-being. Contraceptives are targeted at healthy women in the prime of their lives, and such side-effects cannot be sidelined as "non-serious". Similarly, the study does not even look into possible side-effects like mood changes, loss of hair or loss of libido which are also of concern to women users.

- Breast feeding is a contra-indication for DMPA. The administration of DMPA during lactation could have a serious adverse effect on the health of breast feeding women because of its association with demineralisation of bone. This is in violation of international norms and ethics as put down by $\mathrm{WHO}$ and $\mathrm{ClOMS}$ guideline number 11 .

Many studies quoted in favour of Depo-Provera have been scrutinised and challenged for their veracity. We believe there is no scientific/medical justification for the introduction of injectable contraceptives like Depo-Provera or Net-En.

Dr C Sathyamala in her monograph (1) articulates the problems associated with DMPA and concludes that it is hazardous to the health of women and their progeny. It is not suitable for nulliparous women, adolescents, breast-feeding women, women who have completed their family, and women in the reproductive age group. The evidence available is already damning and it would be unethical to subject more women to clinical trials with these contraceptives.

\section{Drugs Technical Advisory Board recommendation against Depo Provera}

The recommendations made at the Drugs Technical Advisory Board meeting held on February 16, 1995 state that: "DepoProvera is not recommended for inclusion in the Family Planning
Programme." N H Antia, one of the members of the DTAB, in a separate note states why it should not be included:

- The target-based approach may lead public health personnel to impose DMPA on women without checking for contraindications or explaining hazards including permanent sterility.

- Because of the almost superstitious belief in the power of injections, "gullible women would be more than willing to use this injection thus rendering themselves vulnerable to misuse of DMPA".

- The health of the DMPA user has to be monitored for an array of disturbing side-effects. The Indian public health system is inadequate for this work.

- Up to two-thirds of women on DMPA experience menstrual chaos, which may be culturally unacceptable to women.

\section{Lack of informed consent}

Right from the experience in Patancheru in Andhra Pradesh in 1985 (leading to the filing of a writ petition in the Supreme Court), where poor, illiterate women were recruited in clinical trials and administered the Net En injectable without their informed consent, women's groups have monitored the violations of informed consent while administering contraceptives. A study (2) reveals that women in Delhi were put on injectable contraceptives in a public health set-up without informed consent. Vital information regarding its safety and adverse effects was withheld from women, depriving them of the right to make an informed choice.

The empowerment of women is not simply a matter of offering them more contraceptive technologies without complete information, proper screening and follow-up. The attempt to justify the introduction of injectable contraceptives on the plea that it would provide women with a wider range of contraceptive "choice" makes a mockery of the concept of "choice" given that an overwhelming majority of women have no choice regarding access to health, education or employment.

We urge you to consider these issues very seriously before considering any proposals that recommend the inclusion of injectable contraceptives in the National Family Planning Programme. We hope you will reject the interests of private profit and work instead to formulate a policy that ensures the overall good for women and their progeny.

The complete list of signatories has not been carried here for space reasons. It can be seen on the IJME website.

\section{References}

1. Sathyamala C. An Epidemiological Review of the Injectable Contraceptive Depo-Provera. Medico Friend Circle and Forum for Women's Health, Mumbai, 2000 and 2001.

2. SAMA. Unveiled reality: a study on women's experiences with Depo-Provera, an injectable contraceptive. SAMA, Delhi, 2000. 